\title{
Sebastián de Miñano: un periodista del período liberal
}

\author{
JESÚS CASTAÑóN \\ Escuela Normal de Valladolid
}

Sebastián de Miñano y Bedoya nació en Becerril de Campos (Palencia) el 20 de enero de 1779 '.

Fue hijo del Corregidor de dicha villa, don Andrés Genaro de Miñano y. Las Casas ${ }^{2}$, y de doña Margarita de Bedoya y Morrondo.

Realizó estudios en su villa natal, en el Seminario Diocesano de Palencia y en Salamanca, donde cursa Derecho y, en secreto, Medicina.

1 Ochoa, Eugenio de: Apuntes para una biblioteca de autores españoles en prosa y verso, II. Baudry, París, 1840.

- Museo de las familias, segunda serie, año XVII, 1859.

- Id. id. B. A. E. LXII, 1870, como introducción a los Lamentos...

Aguilera, Ignacio: «D. Sebastián de Miñano y Bedoya. Bosquejo biográfico». B. B. $M . P$., año XII, 1930, y XV, 1932.

Redondo Aguayo, Anselmo: «Historia de la villa de Becerril de Campos y sus hijos más ilustres», P. I. T. T. M. Diputación de Palencia, 1953.

Castañón Díaz, Jesús: «Personalidad y estilo de Sebastián de Miñano», P. I. T. T. M., 28. Diputación de Palencia, 1969.

2 Morange, Claude: «Semblanza del Corregidor de Becerril de Campos Andrés de Miñano y Las Casas», P. I. T. T. M., 44. Diputación de Palencia, 1980. 
En 1794 realiza a la perfección la autopsia de un ganadero asesinado en Trujillo, lo que deja al descubierto sus ocultas inclinaciones a la Anatomía y provoca la indignación de su padre, que decide impedir su vuelta a Salamanca y colocarle como familiar del Cardenal Lorenzana, Arzobispo de Toledo, encargado entonces de la educación de los hijos de don Luis de Borbón, hermano del monarca Carlos III.

En 1795 figura ya Miñano como amigo y encargado del hijo mayor, don Luis de Borbón, más tarde Cardenal de Sevilla.

Desde 1799 aparece en Sevilla como oficial de secretaría de su amo, del que llegará a ser Secretario de Cámara.

Allí traba íntima amistad con el grupo de intelectuales formado por Arjona, Reinoso, Lista ${ }^{3}$, José M. ${ }^{a}$ Blanco... Allí dio asimismo pruebas de su reciedumbre de carácter al abandonar el 1 de octubre de 1800 , en plena peste de cólera, la finca en que vivía con su señor para arreglar asuntos del palacio arzobispal en Sevilla. Tales servicios le fueron premiados con una prebenda entera en la catedral de Sevilla, y que seguía disfrutando en Madrid entre 1801 y 1804, como diputado de dicho cabildo en la capital de España.

De 1804 a 1812 permanece en Sevilla. En el año 1810 fue el único miembro del cabildo que no firma el reconocimiento como rey de José Bonaparte, siendo encarcelado a continuación durante 42 días en la cárcel del Santo Oficio.

En 1814, por decisión propia, se volvió afrancesado ${ }^{4}$ y siguió al Mariscal Soult en su viaje a Francia. De 1817 a 1831 fija su residencia en Madrid. A partir de 1832 se establece primero en Bayona en compañía de Lista, con quien colabora en la Gaceta de Bayona y posteriormente en San Sebastián, donde crean la Estafeta de San Sebastián, de la cual es prácticamente fundador y mantenedor ${ }^{5}$. A dicha ciudad entregará en 1843 el legado de su valiosa biblioteca ${ }^{6}$.

3 Juretske, Hans: Vida, obra y pensamiento de Alberto Lista, C. S. I. C. Madrid, 1951.

4 Juretske, Hans: Los afrancesados en la guerra de la Independencia. Biblioteca del Pensamiento Actual, n. ${ }^{\circ} 117$, Madrid, Ediciones Rialp, 1962.

5 Miñano comentará en una carta que Lista y él van a todas partes juntos como la mona y el mazo.

6 López Alen, Francisco: La Biblioteca Municipal de San Sebastián. Imprenta I. Baroja e Hijos, San Sebastián, 1908.

Mendiola Querejeta, Rufino: «La Nueva Biblioteca Pública de San Sebastián». R. B. A. M., LVIII, 1951, 121-132. 
El 6 de febrero de 1845, a las dos de la tarde, según testimonio de su hijo y biógrafo, Eugenio de Ochoa, fallece en el número 22 de la plaza de Armas o de la Libertad de Bayona. bastián.

Sus restos serán depositados en el viejo cementerio de San Se-

Entre su numerosa bibliografía, en gran parte irreparablemente perdida, cabe destacar: Diccionario Geográfico Estadístico de España y Portugal. Imprenta de Pierrat Peralta, plazuela del Cordón, 1, Madrid, 1826 (10 tomos más un apéndice, realizados para los suscriptores entre 1826-1829); Historia de la revolución de la Medicina (versión de la obra de Cadanis); traducción de La Revolución Francesa, de Thiers (con extensas notas y añadidos); Condiciones y semblanzas de los Diputados a Cortes para la legislatura de 1820 y 1821, Madrid, en la Imprenta de don Juan Ramos y Cía., 1821; Discurso sobre la libertad de. imprenta (presentado a las Cortes de 1820 en la primera legislatura, que probablemente tenga que ver con el artículo de la misma temática aparecido en $\mathrm{El}$ Censor); Los usos y derechos imprescriptibles del pueblo soberano por excelencia; Relación histórica de la batalla de las Platerías (sátira de un motín callejero de Madrid); Ingratitudes del pueblo español; Sesiones de las Cortes interceptadas por esos caminos; Los Arístides modernos; Carta a un amigo sobre la purificación y la amnistía (enviada a don Juan Grijalba, secretario de la Real Estampilla); Carta a un amigo sobre el Consejo de Estado; varios artículos firmados, publicados entre 1841 y 1842 en la Revista Enciclopédica de la Civilización Europea, que dirigían Patricio de la Escosura y Eugenio de Ochoa; "Cuadro comparativo entre la España de hace sesenta años y la actual» (Revista Enciclopédica de la Civilización Europea, París, mayo de 1843, tomo III), reproducido en Costumbristas Españoles, Editorial Aguilar, 2a . edición, Madrid, 1964, i. 683-691; «Dos Nuevas Cartas del Pobrecito Holgazán» (dadas a conocer en «Opúsculos Inéditos del Doctor don Sebastián Miñano», Revista Hispano-Americana, 1848, págs. 95,129 y 521) y un sinfín de cartas posiblemente perdidas para siempre, más un sinnúmero de artículos anónimos (entre ellos los que le atribuye Jurestchke en su Vida, obra y pensamiento de Alberto Lista) que, cuando sean debidamente estudiados, nos presentarán, sin duda, una nueva perspectiva de Miñano.

\section{FOLLETINISTA Y PERIODISTA POLITICO}

Por encima de tan dispersa y tan vasta erudición, por encima de su famoso Diccionario, hay que destacar su labor periodística, Lamentos 
politicos de un Pobrecito Holgazán que estaba acostumbrado a vivir a costa ajena. Carta Primera: y, si gustare, no será la última. El Lamentador. Madrid, Imprenta de Alvarez, 1820.

Debió de aparecer, según Claude Morange (que viene preparando desde hace más de una quincena de años una extensa tesis doctoral sobre Miñano), entre el 27 y el 31 de marzo ${ }^{7}$. Forma con Cartas de Don Justo Balanza a un Pobrecito Holgazán, Madrid, Imprenta que fue de García, $1820^{8}$, y «Cartas de un madrileño a un amigo suyo de provincias») (El Censor, 7-X-1820 a 16-III-1821) una curiosa y continuada trilogía apasionada y entrecortadamente escrita por «Chano» en el breve período de un año. Se baraja a lo largo de la misma - como se prueba con textos antológicos - la compleja personalidad del hombre (el canónigo y el padre de familia; el afrancesado primero y agente secreto de Fernando VII después...) y del escritor satírico-costumbrista, ideólogo avanzado, exaltado defensor de toda libertad, autor de una sátira romántico-corrosiva...:

Pero lo que yo quisiera es que esos señores prudentones me dijesen en qué consiste la ventaja de la libertad de escribir consagrada en nuestro código, si ésta no ha de emplearse jamás en corregir los abusos de aquellos a cuya altura no alcanza otro azote que el de la imprenta. Desde que me nacieron los dientes hasta el 7 de Marzo del año pasado de 1820, es decir, durante algo más de cuarenta años, le puedo a usted jurar, a fe de hombre honrado, que siempre y por siempre he visto que se disfrutaba en España una libertad absoluta de imprenta en el sentido en que la entienden esos pozos de prudencia. Yo he visto publicar injurias y especies ciertas y falsas contra los padres jesuitas después que fueron expatriados por real orden del señor don Carlos III, sin que nadie denunciase al escritor; yo he leído por mis ojos las mayores alabanzas de los institutos monásticos y las diatribas más atroces contra todos los que directa o indirectamente aconsejaran su extinción; yo he visto proferir y ejecutar venganzas sin cuento contra los que se presumía que aprobaban las ideas de la libertad que proclamaba una nación vecina; yo he visto escribir con la mayor libertad e independencia libros enteros en que se ridiculizaba al gobierno representativo, al paso que se encomiaba hasta las nubes el arbitrario y despótico; yo he visto publicar libremente las ideas más absurdas sobre la inmunidad eclesiástica, sobre los privilegios del clero y de la nobleza, y sobre otros mil asuntos que ahora se miran, y con razón, como otros tantos gravámenes de que es preciso libertar a la sociedad. Pero sobre todo, cuando he visto más noblemente desplegarse esa especie de libertad de imprenta ha sido desde el año catorce acá. Dígaseme, ¿qué nación gozó jamás de una libertad más absoluta y más premiada, que la que hemos disfrutado en Espa-

7 Morange, Claude: «Los lamentos políticos de un Pobrecito Holgazán, 1826». P. I. T. T. M., 37, Diputación de Palencia, 1976.

8 Cartas de D. Justo Balanza (C. D. J. B.). 
ña, para decir toda especie de vituperios y contumelias contra esos mismos liberales, y contra todas las ideas que se les antoja atribuirles?

(«Cartas de un madrileño», $\left.15^{\mathrm{a}}.\right)^{9}$.

Decidido, pues, a cambiar las tornas en el juego de la «engañada» opinión pública, Miñano se lanza en tromba al apasionante mundo del folletín y del periodismo político, proclamando - ya casi al final de la aventura- el poder implacable del arrojadizo dardo de la sátira, en el que pronto se sentirá maestro de maestros.

Con su habitual técnica de contraposición violenta de la tiranía y el liberalismo define en la misma carta la misión del escritor satírico y da, a la vez, una lista de temas a emplear por tal clase de escritores, a la luz de la oposición. Resulta así un contrastante cuadro satírico y una defensa de la ruptura del silencio amordazado por la censura, que Miñano acaba de romper violentamente a la sombra de la nueva ley de la libertad de imprenta:

Un escritor satírico, dicen ellos, no tiene necesidad de atacar los vicios de ciertas y determinadas personas, aunque vea claro como la luz del día que de ellas solas depende el bien o el mal de toda la sociedad. Bastante campo le ofrecen los vicios y los defectos generales de todos los tiempos, sin asestar sus tiros contra la ignorancia o mala fe de los que tienen en su mano los destinos de los hombres. ¿Por qué no emplean las sales del ridículo y el amargo de la ironía contra aquellos abusos que reinaron en otro tiempo y que probabilísimamente no volverán a producirse en la sociedad? ¿Por qué no pegan de firme contra los mayorazgos que ya se concluyeron, contra la Inquisición que se abolió, contra los monacales que ya están extinguidos, contra el Consejo de Castilla que está disuelto, contra los abates que desaparecieron hace miles de años, y contra todo lo que ya no es temible ni puede defenderse?

\section{I.-LAMENTOS POLITICOS}

\section{Costumbrismo inicial}

Sebastián de Miñano y Bedoya irrumpió en la literatura folletinesca del Trienio Liberal con sus inigualables, difundidísimos ${ }^{10}$ y limitadísimos Lamentos de un Pobrecito Holgazán, primera serie de esta trilogía epistolar.

9 Por su falta de valor diacrítico y para mayor comodidad del lector actual, modernizo la ortografía de los textos.

10 Morange, Claude: Op. cit., pp. 243-244, afirma: «en menos de un mes, y en Madrid, se habían hecho una impresión y cinco reimpresiones de 1.500 ejemplares, esto es, 9.000 ejemplares en total, de la Primera Carta.» Ochoa asegura que entre España y América se vendieron más de 60.000 ejemplares de los Lamentos. 
De la fina ironía de las 10 cartas destaca la primera, con esta hábil entrada:

Señor don Servando de Mazorra.- Muy Sr. mío:

¿Con que ya tenemos constitución? ¡Qué escándalo, qué horror, qué desvergüenza!... ¡En qué tiempos vivimos!... Y qué desgracia ha sido la nuestra de haber alcanzado este maldito siglo XIX!...

Por parecidos linderos satíricos, en un torno a la vez gracioso y levemente sarcástico, transcurren las restantes, especialmente desde que en la carta quinta se introduce en forma hábil de nota final la carta del "Alcalde Preguntón», en que este personaje, amigo de don Servando, ruega al Pobrecito Holgazán le dé la certera fórmula para poder cumplir con las nuevas exigencias constitucionales sin dejar de seguir haciendo, en cambio, todo lo que le venga en gana.

El total de los Lamentos constituye una feroz sátira social de la que no está exento el propio Miñano, que más de una vez se introduce, con chispa, dentro del relato, a lo largo de cuyo caminar el autor se ve conocido y admirado, envidiado y odiado simultáneamente.

Desde la carta tercera se editan los Lamentos en la Imprenta que fue de Fuentenebro.

Tras la sexta, tal vez excesivamente animado por su éxito, Miñano intenta hacer panfletismo en serio, publicando las C. D. J. B., aunque a mediados de mayo volverá a sus habituales Lamentos (Carta $7^{\mathrm{a}}$.).

En 1848 Ochoa publica otras dos cartas inéditas (Revista Hispanoamericana) que, según Claude Morange, parecen pertenecer a 1822.

En 1870 el propio Ochoa reimprime los Lamentos en el tomo 62 de la B. A. E., precedidos de una favorable reseña biográfica.

Ultimamente Valeriano Bozal ha vuelto a reimprimirlos en edición de bolsillo (edit. Ciencia Nueva, Madrid, 1968).

\section{II.-IDEOLOGIA Y ETICA}

\section{Cartas de D. Justo Balanza}

Tal vez la mejor y más sencilla forma de contemplar directamente lo exaltado de la ideología anticonservadora de Sebastián de Miñano sea recopilar una breve antología temática.

El móvil de la exaltación ideológica va subiendo permanentemente 
de tono hasta las cotas de la carta $13^{\text {a }}$. (de las del Madrileño), sancionada como «altamente incitadora a la desobediencia» y frustrantemente perturbadora de la mente del escritor, que todavía intentará justificarse y ratificarse en sus opiniones en otras cinco cartas, en las que no reconoce culpa alguna y se pronuncia a su vez contra sus propios jueces con una desengañada amargura - muy romántica por otra parte- $-\mathrm{y}$ muy en el extremo opuesto de las desenfadadas, triunfantes y ya lejanas «pepitorias semanales de retratos».

El predominio de la idea sobre el fondo lleva asimismo al desencanto del estilo, sobre el cual opinará repetidamente el propio autor, intentando justificar bajo la densidad de la idea el cambio y el descuido del estilo satírico, aquí ya altamente corrosivo y prácticamente opuesto al de los Lamentos $^{11}$.

En la carta $1^{\text {a }}$ (C. D. J. B.), escrita todavía en alternancia con los Lamentos, se vive mirando hacia el recuerdo. A partir de la $2^{\text {a }}$. esboza ya la motivación y el nuevo estilo en términos más serios y bastante más agrios:

Pero si algún periodista de aquellos que han tomado por insignia la desvergüenza y por lema la estupidez, se viniese todavía con artículos tan asquerosos como los que han publicado hasta ahora, lejos de abatirme a contestarlos, me parece que se les deben dar muchas gracias por dos grandes servicios que hacen a un tiempo: el primero, atacando sin razones, que vale tanto como una defensa; y el segundo, acelerando el fin de su periódico, que es el mayor favor que pueden hacer a las gentes honradas.

(C. D. J. B. $-2^{\mathrm{a}}$.)

Inquisición

Lejos de ser la Inquisición un objeto de ataque en España, no es, ni puede ser más que un objeto de desprecio, o por mejor decir, un dato histórico para pintar los delirios y extravagancias del entendimiento humano.

(Ibíd.)

Ese sacrílego tribunal que debe considerarse abolido desde fines del último siglo, es decir, desde que fue un general objeto del odio, del sarcasmo y del desprecio de toda la nación.

(Ibíd.)

11 El parecido con el seudónimo de Larra «El Pobrecito Hablador» ha sido señalado ya por G. Le Gentil en su estudio sobre Bretón de los Herreros, en 1909. 
En una palabra, la Inquisición está ya en el mismo caso que las brujas, los vampiros, los duendes, las posesiones, las obsesiones diabólicas y otra multitud de invenciones que fueron de moda en algún tiempo, pero que ya nadie considera dignas ni de refutación ni de ridículo.

(Ibíd.)

\section{Consejo de Castilla}

Este sí que es un cuadro verdaderamente ridículo, sobre el cual ha podido V. y aun debido derramar toda la acritud de la sátira, porque es sobremanera importante ilustrar a toda clase de vulgos y correr enteramente el espeso velo con que ha estado encubriéndose a los ojos no sólo del pueblo gobernado, sino también de los monarcas gobernantes. Todos cuantos actos, atribuciones y regalías ha ejercido el Consejo desde el día mismo de su creación, exceptuando la administración de justicia en grado de apelación, han sido otras tantas usurpaciones y atentados contra la nación o contra el Rey.

(Ibíd.)

Si nos pusiesen en la dura alternativa de escoger entre Consejo de Castilla tal como lo hemos conocido, o Inquisición religiosa tal como ya estaba en estos últimos tiempos, no deberíamos dudar un punto en preferir esta última como infinitamente menos funesta a las luces y progresos del entendimiento humano.

(Ibíd.)

Diezmos

Fija V. si no me engaño el máximum de la cuota que se paga bajo el nombre de diezmos en un cincuenta por ciento del líquido que le queda al labrador después de haber deducido sus gastos y sus anticipaciones, ¡Pero ay, señor Holgazán, y cómo se le conoce a V. lo poco que ha meditado sobre una materia de la cual únicamente ha percibido los frutos, sin determinarse a desmenuzar todas las partidas que deben considerarse en el cálculo!

(Ibíd.)

\section{Hospitales}

El hospital general de esta Corte es una de las muchas muestras que da nuestro Gobierno de que siempre su marcha está atrasada en un siglo respecto a lo demás de Europa. Mientras que en ésta se seguía la funesta moda de tener reunida la hospitalidad en un gran edificio atestado de enfermos y de dependientes, nosotros teníamos un hospital para cada enfermedad separada de modo que en un pueblo de 700 habitantes he conocido yo 72 hospitales, y en otro que no está lejos de la Corte, correspondía un hospital a cada 300 habitantes. Pero luego en Europa llegaron a convencerse de que estos vastos es- 
tablecimientos no sólo eran funestos a la salubridad de los pueblos, sino también sumamente costosos por la parte administrativa; entonces se nos ocurrió a nosotros reunir todos los enfermos y todas las enfermedades en un edificio, dotado de muchas rentas y arbitrios, pero sobre todo, bien cargado de empleados con sus respectivos sueldos, de modo que no bajase el costo de la administración de un 40, o acaso de un 50 por 100 . Esta luminosa idea se creyó entonces el non plus ultra de la civilización y de la filantropía, mientras que no era sino una señal de nuestro atraso y de nuestra ignorancia.

(Ibíd.)

Puede asegurarse sin riesgo de equivocación que con la mitad de la suma que cuesta cada enfermo en la hospitalidad general, sería socorrido y curado al lado de los suyos por medio de la hospitalidad domiciliaria; y si a esto se agrega el enormísimo ahorro que resultará de la disminución de empleados, coste de los edificios y simplificación de la parte administrativa, aún podría estrecharse más el cálculo.

(Ibíd.)

\section{Secularizaciones}

Desde que se negó el primer pase a la primera bula del primer fraile que se quiso secularizar, se cometió en esta línea el primer atentado contra la lenidad y mansedumbre de la Religión de Jesucristo, que desconoce y repugna esas violencias tan ajenas del espíritu de caridad que imprimió en ella su divino autor. Un religioso que se seculariza es un nuevo ser que adquiere la sociedad, y una ganancia positiva que hacen la Iglesia y el Estado. Lejos de ponérsele trabas y dificultades para realizar sus deseos, debieran ofrecérseles premios y estímulos para que se apresuraran a volver a ser miembros de la masa común, que acaso abandonaron por falta de reflexión o por una violencia moral.

(Ibíd.)

Cultura

Yo no dudaría en afirmar que la principal causa de nuestro atraso y de nuestra ignorancia consiste, no tanto en lo que hemos dejado de leer, cuanto en calidad de los libros que hemos leído.

$$
\text { (C. D. J.B. } \left.-4^{\mathrm{a}} .\right)
$$

Desde la edad más tierna sólo se ponen en manos de los jóvenes aquellos libros que, sin prestar la menor luz a sus entendimientos, logran trastornar las bases del buen juicio haciéndoles caminar de hipótesis en hipótesis hasta conducirlos a que miren las verdades como errores y los errores como verdades.

(Ibíd.) 


\section{Censura}

El juzgado de imprentas seguía perfectamente el ejemplo que refiere Montesquieu de los Escitas, los cuales sacaban los ojos a sus esclavos a fin de que no se distrajesen cuando estaban haciendo la manteca.

(Ibid.)

¿Quién creería que mientras al público de Madrid se le estaba regalando con la Villana de Vallecas, el Diablo Predicador, y otras todavía más disparatadas y sucias, se hallasen severamente prohibidas todas las comedias de Moratín? Ese hecho solo y aislado da una idea más cabal del espíritu que regía la censura en España que cuantas descripciones serias o jocosas se intenten hacer de su juzgado o tribunal.

(Ibíd.)

\section{Los lechuzos}

¿Válgame Dios y cómo se mete Vm. hasta los codos en este trillado asunto y cómo se echa de ver el gozo con que describe la multitud de sacaliñas, que asaltan al labrador al tiempo de la cosecha!

Sólo el que haya vivido en el campo o en las aldeas podrá formar una idea clara de la fuerza moral con que se arrancan, por vía de limosna piadosa, unas cantidades que, si se aplicaran a otros objetos de la beneficencia pública, serían acaso suficientes para hacer desaparecer de nuestra vista todos los espectáculos dolorosos de la mendicidad. En vano se encuentran algunos labradores ilustrados que conocen lo inútil y aun perjudicial de semejantes limosnas, y que se abstendrían de darlas si sólo hubiesen de consultar su voluntad; en vano expresan su disgusto dentro del círculo de sus familias, porque, a pesar de todo, tienen que acomodarse a la costumbre so pena de ser calumniados por todos los partidarios del lechuzo demandador. Este no se olvida nunca de decir en confianza a todo el que quiere saberlo cuánto le han dado en casa de fulano y cuánto en casa de ditrano, explicando a su manera las causas de lo que él llama mezquindad. Allí salen a colación las exclamaciones acostumbradas contra las nuevas doctrinas, los libros venenosos, la falta de piedad, el libertinaje de estos tiempos, por fin y postre, la herejía, que es como si dijéramos la bala roja con que se destruye y aniquila la reputación mejor sentada. No contentos con difamarle en secreto, se aprovecha también la coyuntura del primer sermón que ocurre para hacer caer el discurso y llamar la atención del auditorio sobre los enemigos de nuestra Santa Religión, que en boca de los lechuzos nunca son otros que aquellos que no se dejan saquear por manos de sus reverendísimas. El P. se enfervoriza, da media vuelta en el púlpito y echa su mirada o miradas expresivas para que el auditorio comprenda que no se dice por todos, sino por alguno que me está oyendo. Esta especie de amenaza surte tan bellos efectos, que por más que aquel vecino haya hecho ánimo de resistir los asaltos de la alforja, no tiene más remedio que acomodarse al estilo si quiere que le dejen en paz.

(Ibíd.) 
[...] Todos murmuran de los frailes, de sus trajes, de sus maneras, de su lenguaje, de sus usos y finalmente de todo lo que les constituye tales, y, sin embargo, todos de fuerza o por fuerza contribuyen a su manutención y existencia.

(Ibíd.)

\section{Mayorazgos}

Empapado en esta idea he creído absolutamente inútil dar ninguna educación al primogénito que es el que ha de sucederme. Quiero decir que le he evitado los fatales ratos que se hacen sufrir a los jóvenes para que aprendan la gramática latina, filosofia, leyes, cánones o teología; pero en cambio el mayorazgo tiene un birlocho muy lindo, y sabe manejar un tronco de caballos tan bien como su cochero: monta bastante bien a caballo, y empieza a leer y escribir medianamente, que es lo que más necesita para hacer un papel brillante en la sociedad. Tiene un ayuda de cámara que cuida de su persona, y le instruye al mismo tiempo del tono con que debe tratar a sus hermanos y hermanas para acostumbrarlos a la idea de que le miren como a único dueño de todo lo que naturalmente debiera ser de todos.

(Ibíd.)

La introducción de los mayorazgos fue un acto de tiranía superior a todos los ejemplos que el despotismo oriental ha presentado jamás al mundo y parece increíble que nosotros, que miramos con tanto aire de desprecio y de compasión a los turcos, estemos dando una prueba perenne de que en ciertas cosas estamos más atrasados que ellos.

(Ibid.)

Las vinculaciones, después de los diezmos, son la primera y principal causa de todos los males que nos afligen [...] Tan perjudiciales son los grandes mayorazgos como los pequeños y medianos y no hay más razón ni pretexto para conservar los unos que los otros...

(Ibíd.)

\section{Sermones}

Confieso que no es prudente inculcar demasiado sobre un punto tratado ya con tanta maestría por el autor del Gerundio; pero como, por desgracia, son tantas y diferentes las especies de Gerundios y Gerundias, que unas saltan a los ojos de todos los oyentes y otras sólo son percibidas por los que tienen alguna ilustración, convendrá detenernos algún tanto en manifestar los perjuicios que resultan de valerse del público como de un instrumento necesario para la política y para la consolidación del poder.

(C. D. B. J.- $5^{\text {a }}$ ) 
Religiosas

Pobrecitas, casi me da lástima el hablar de ellas sabiendo que por más que se predique no ha de haber modo de que el gobierno se penetre de la necesidad de redimir de la miseria y de la opresión a tantas víctimas de la seducción, del engaño, de la inexperiencia y del falso celo. Entregadas desde la edad más tierna a la dirección espiritual de ciertos hombres, cuyo menor defecto suele ser la manía de hacer esa especie de conquistas en que se supone muy interesado al cielo, fácilmente se persuaden a que son expresamente llamadas a hacer una clase predilecta entre las escogidas del Señor.

(Ibíd.)

\section{Pretendientes}

Yo, pecador de mí, también me río y me río sin poderlo remediar cuando veo toda esa chusma de hambrientos con sus sombreros debajo del brazo, su memorial en la mano derecha, su casaquita raída y su cuello barnizado de almidón.

(Ibíd.)

¿Qué sería de nosotros si conforme les ha tomado a los hidalgos la manía de no ser artistas, labradores ni artesanos, hubiesen dado también en la de no ser oficinistas? ¿En qué quiere Vm. que viniesen a parar todos esos hermanos no mayorazos, si no tuvieran el arbitrio de las togas, las iglesias, las encomiendas, las frailerias militares y las plazas de Hacienda?

\section{Empleomania}

Si se quiere que no haya empleo-manía, es menester empezar por destruir la diezmo-manía, la vínculo-manía, la teólogo-manía y, sobre todo, la consuetudo-manía, por la cual se miran como respetables una multitud de instituciones que ni producen ni han producido de mucho tiempo acá otro fruto que el de alimentar holgazanes como $\mathrm{Vm}$. y yo y las nueve décimas partes de los habitantes de España.

(Ibíd.)

La ironía amarga y oscura, el anticlericalismo, la discrepancia total con las instituciones tradicionales como el Consejo de Castilla y la Inquisición no nos han mostrado ya la otra cara -agriamente críticadel simpático Sebastián Miñano de los Lamentos.

Entre nublos de diezmos, mayorazgos, oratoria sagrada y otras especies por el estilo, el panorama se ha ensombrecido tanto que deja muy atrás, en intensidad crítica, escritos de Espronceda y de Larra o de los regeneracionistas, a los que gana en furor crítico e independencia de criterio. 


\section{Cartas de un madrileño}

Una breve ojeada a las Cartas de un madrileño a un amigo suyo de provincias nos presenta al Miñano adoctrinador político, revolucionario exaltado, que pretende estar por encima de los demás mortales -muy especialmente por encima de la clásica ingenuidad de los provincianos - y aún del propio gobierno, a quien se cree obligado a instruir en cuestiones de patriotismo y especialmente en la exaltación continua de la libertad.

Por una ironía, muy de Chano, se hace la alabanza de la corte (más bien una auténtica corte de los milagros) y el menosprecio de la aldea (lugar, sin duda, menos rico en la mina de acontecimientos de interés político-periodístico).

Frente a la fría ordenación temática de las $C . D . J . B$, abunda aquí el desorden caótico y el apasionamiento exaltado:

Llegó, por fin, el deseado tiempo de que pudiésemos explicarnos sin temores; y no encontrando usted en quien vengarse de su forzado silencio, me acosa y me persigue para que cada correo le escribá un proceso de todo cuanto pasa en el mundo, como si no le bastase la lectura de todos los papeles públicos. Estoy de acuerdo con usted en que los habitantes de las provincias no pueden formar un juicio claro de los hechos si se contentan con la relación que de ellos se hace en los diarios de la capital, porque cada uno suele referirlos a su modo o por lo menos varían infinito en las observaciones que de ellos sacan.

(C. $\left.M \cdot-^{\mathrm{a}} \cdot\right)^{12}$

Como la Constitución, a pesar de su enorme peso legal, no ha podido reformar aún el país al acelerado ritmo del pensamiento de nuestro autor, Miñano vuelve de nuevo a la eficacia literaria del cuadro de costumbres, ahora denso y sombrío, oscurecedor del panorama:

Quisieran que el sistema de hacienda se reformase sin hacer la menor novedad ni en los empleos ni en los empleados; que el clero regular desapareciese por sí solo [...] y que [...] costase menos al Estado, sin que ningún individuo dejase de ser tan rico y privilegiado como lo era antes. En una palabra, quisieran que navegase la embarcación sin que se abriesen las aguas para darla paso.

(Ibíd.)

No he podido menos de reírme con las preguntas que me hace usted de si a pesar de la Constitución continúan en Madrid los petardistas en tan gran número como abundaban antes; si se reúnen todavía los parásitos en la Puerta del Sol al acercarse las horas de comer; y si se encuentran todavía aquellos ejemplares de gente vestida de negro que, con sus legajos debajo del brazo y 
sus humeantes cigarros en la boca, inundaban la calle Mayor y todas las bocacalles inmediatas a los Consejos.

La respuesta supera las sombrias visiones quevedescas y raya, a mi entender, en el esperpento valleinclanesco:

Tiempos hubo en que los petardistas se pudieron contar en Madrid no sólo por clases sino también por individuos [...] Pero en el día [...] iválgame Dios qué diluvio de tramposos y petardistas se ha descolgado de todas partes!

(Ibíd.)

Por lo que hace a los parásitos es cosas que mete miedo, porque con la nueva costumbre de comer a media tarde se juntan como llovidos en oliendo que hay un par de principios de cualquier mesa.

Desde las niñas más tiernas hasta las viejas más arrugadas y carcamales no saben dar una respuesta sin que vaya acompañada de una porción de hortalizas de aquellas que dan peor olor. Yo no sé si esto hace parte de la magencia o si es condición esencial del manolismo; lo que sí puedo decir es que el que quiera aprender amabilidad, dulzura y limpieza de lenguaje, no tiene más que dirigir la palabra a las ciudadanas de casi todos los barrios de la capital y podrá formar un diccionario de desvergüenzas que sirva de ejemplo para instrucción de los presidiarios. Los hombres más abandonados y obscenos de la playa podrían pasar por unos cartujos al lado de cualquier mujerzuela madrileña.

¿Mas que tiene de extraño este vicio, cuando muchas gentes que pasan por ilustradas y otras que aspiran al renombre de patriotas aplauden y celebran este groserísimo desparpajo? ¿Quién quiere usted que no recargue en ese asqueroso modo de producirse, cuando ésta es la única prueba que suelen dar algunas personas de su acendrado patriotismo?

(Ibíd.)

El sarcasmo se va acentuando cada vez más, especialmente al tratar el tema de la libertad de imprenta o al hacer referencia a religiosos, ecleśiásticos, falsos patriotas, pretendientes a los altos puestos...:

¿Habrá persona que dude de los trabajos y penalidades que han padecido algunos infelices durante estos últimos seis años, metidos en este Madrid, y sujetos al triste sueldo de cuarenta mil reales? ¡Ay cuántos suspiros les costaba tomar aquel dinero inconstitucional! Yo les vi a muchos de ellos envueltos en sus capas durante el invierno, y con su bastoncillo ligero durante el verano, que era una compasión el mirarlos. ¿Pues qué me dirá usted de los que guardaron un pedacito de la lápida envuelto en un papel con riesgo de sus vidas? ¿Y los que llevaron su heroísmo hasta el punto de tener guardado debajo de la estera un ejemplar de la Constitución? ¿Qué premio habrá que baste a recompensar la fortaleza de aquellos que se atrevían, en medio de las persecuciones del despotismo a rezar un padrenuestro a solas por el alma del difunto Laci? ¿Y los que tuvieron la constancia de no suscribirse a la Gaceta durante este tiempo?

(C. $\left.M \cdot-4^{\mathrm{a}}.\right)$ 
Si es que tiene usted pensado venirse una temporada a Madrid, véngase cuanto antes, porque es cosa de alquilar balcones para ver y oír lo que está pasando sobre las propuestas y provisión de las plazas del Estado [...].

¡Oh dichosa España y siglo venturoso, en que por más vacantes que se imaginen y por más difíciles que sean los encargos que haya que desempeñar, se encuentran centenares de pretendientes entre los cuales se puede escoger como entre peras, sin riesgo de que el elegido valga dos de dos más que el que fue desechado!

(C. $\left.M \cdot-5^{\mathrm{a}}.\right)$

\section{En un largo in crescendo - que culminará en la sancionada Carta 13- el autor empieza ya a trasformar su clásica «pepitoria de retratos» en una sangrante y avinagrada «pepitoria de caricaturas», fundamen- talmente nutrida de políticos;}

Entretanto lo doloroso es que, por no chocar de frente con esta y otras preocupaciones, se ven los señores diputados en la dura precisión de tomar medidas medias contra lo que les dicta su razón y, acaso acaso, su conciencia. Así verá usted que nos hallamos con medios frailes, medios mayorazgos, medios diezmos, media libertad de imprenta, medio Consejo de Estado, media instrucción pública y aún media inquisición religiosa. Sólo de hacienda, de éjercito y de marina es de lo que no tenemos ni mitad, ni siquiera cuarterón, respecto de lo que necesitamos en el día

(Ibíd.)

Mísera y precaria sería la existencia de la Constitución si estuviese ligada a la fortuna de algunos particulares, por ilustres y beneméritos que ellos se crean. La Constitución es el patrimonio de todo el pueblo y sólo el pueblo. Y el pueblo todo entero es quien ha de sostener y disfrutar esta preciosa herencia.

$$
\text { (C. M. }-6^{\mathrm{a}} . \text { ) }
$$

De aquí inferirá usted cuán cierto es lo que le he dicho muchas veces, a saber: que los verdaderos enemigos de la Constitución no son los nobles, ni el clero, ni los frailes, ni los serviles, ni los cesantes, ni los persas, sino esa multitud de pretendientes ambiciosos de empleos; ese enjambre de aspirantes a premios, que van todos los días a insultar al Congreso con sus ridículas y extravagantes pretensiones; esa gavilla de acaparadores de destinos, que han sabido repartirse las plazas más lucrativas sin dar el más leve indicio de pudor; esa malhadada sed de venganza que traspira por medio de las voces de compasión, de olvido y de beneficencia.

(Ibíd.)

Bien me parece lo que usted me decía en su última carta acerca de la exactitud con que ese buen párroco ha empezado a explicar el espiritu y la letra de nuestra Constitución política, tanto más necesario en esos pueblos, cuanto que son sin disputa alguna los más necesitados de instrucción. Pero yo que los conozco tanto como usted y que he nacido y vivido mucho tiempo entre ellos, estoy en estado de asegurarle que haría mucho más efecto entre ellos ver poner en práctica lo mandado por las Cortes acerca de la continuación de su Canal de Castilla que cuantas explicaciones dominicales puede ha- 
cer el orador más elocuente. Desengañémonos, amigo, y dejémonos de historias, que si los pueblos no son, o dejan de ser constitucionales, no hay que echarle la culpa sino a la falta de pruebas sensibles y materiales de las ventajas que trae consigo la Constitución.

$$
\text { (C. } \left.M \cdot-9^{\mathrm{a}} .\right)
$$

Sólo el genio de la estupidez y del error pudieran haber inventado la idea de exigir ante todas las cosas la calidad de adicto para el nombramiento de un juez, de un jefe político u otra magistratura semejante. ¿Y qué quiere decir adicto? ¿Y cómo se conocen los adictos, y los que no tienen adhesión? ¿Será acaso cantando el Trágala? Pues entonces lo mejor sería que en el plan de estudios se añadiese una cátedra de forzosa asistencia, para que todos los ciudadanos aprendiesen a manifestarse adictos, siempre que lo exigiese la ocasión. Yo creía que las principales calidades de un juez serian la integridad y la inteligencia, suponiendo en ellos, como en todos los demás ciudadanos, la ciega obediencia a lo que manda la Constitución. ¿Pero pedirles que hayan dado pruebas de adictos? El diablo no discurriría así.

$$
\text { (C. } M \cdot-10^{\mathrm{a}} \text {.) }
$$

Me he detenido algo más de lo que debiera en esto de los adictos, porque hace ya mucho tiempo que me están dando cien patadas en el estómago esos majaderos que creen imponer al público con la aplicación de semejante voz; y a ha llegado a tal punto el pedantismo gubernativo que me temo que pronto se pedirá la cualidad de adictos hasta para enseñar el árabe y la veterinaria.

(Ibíd.)

¡Cuántas veces hubiera yo deseado hablar a usted con alguna confianza sobre los sucesos políticos y manifestarle con franqueza mi dictamen acerca de las cosas y de las personas, si al momento estos señores míos no se hubieran arrojado como unos energúmenos sobre mis pobres mamotretos, obligándome a dictar alabanzas en lugar de vituperios y a escribir panegíricos en vez de críticas!

(C. $M .-11^{\mathrm{a}}$.)

La famosa Carta $13^{\mathrm{a}}$., llena de dicterios, constituye una fuerte sátira contra los ministros y su comportamiento público, elaborada sobre la supuesta base de lo primero que haría El Madrileño en el caso de que de la noche a la mañana se viese nombrado ministro.

Por su interés y por su extensión, no cabe sino remitir al lector interesado en el tema al texto original.

En las cinco cartas que la siguen, junto a una obsesiva vuelta a la defensa de lo afirmado en la Carta $13^{\mathrm{a}}$., se reiteran las fervorosas alusiones a la defensa de la libertad de imprenta, los ataques a la antigua censura y la acalorada proclamación de toda libertad, en una búsqueda apasionada de la libertad total:

Aquí llegaba yo de mis reflexiones, cuando un amig̋ mío se presenta en mi casa muy azorado, diciendo que la carta tan sencilla que escribí a usted el correo pasado ha sido denunciada por moros y por cristianos a la autoridad competente. Que los unos la denuncian por sediciosa, los otros por iniuriosa, 
aquéllos por subversiva, éstos por infamatoria, y todos por satírica y archimordiente. Le aseguro a usted, amigo, que pocas cosas me han sorprendido $\tan$ de punto como una novedad que es tan ajena de mis puras y honestas intenciones. (C. $M .-14^{\mathrm{a}}$.) Si se les prohibiera del todo publicar sus pensamientos y hacer alarde de su ingenio, entonces sí que podrían quejarse de nuestra tiranía sacerdotal o como quieran llamarla; pero habiendo tantos santos cuyas vidas se deben escribir y exornar, habiendo tantas obras de teología que comentar, tantos villancicos que componer y tanta medicina que mejorar, ¿cómo pueden quejarse de que no se les deja expedita la libertad de la imprenta?

La Carta $17^{\text {a }}$. constituye una larga defensa razonada de su famosa Carta $13^{\mathrm{a}}$.

La Carta $18^{\mathrm{a}}$. y última, junto a la vuelta obsesiva hacia el mismo tema, incluye una desengañada alabanza del «voluntario retiro» político de su amigo de provincias.

\section{Y termina con esta apesadumbrada despedida:}

Este consuelo ya usted sabe que no es de los que curan las dolencias ni las prisiones. Y así, aunque le dije a usted en mi anterior que las pesadumbres no pagan trampas, ahora le digo con toda seriedad que las pesadumbres acaban por destruir la salud, y la mía está quebrantada por mucho tiempo. Así por esta razón, que es la principal, como porque no conceptúo que estamos todavía en tiempo de decir la verdad, ni aún a los amigos, determino suspender nuestra correspondencia por algún tiempo. Y, en el entretanto, haga usted por contener su curiosidad o diríjase para satisfacerla a otro que no sea

El Madrileño

\section{III.— Estilo y crítica}

Tras el desenfadado estilo satírico del Miñano Lamentador o Pobrecito Holgazán, con su pertinente «pepitoria semanal de retratos», hemos visto levantarse el ultrajante e hiriente -más hiriente cuanto más serio y ordenado, aunque también salpicado de sátira- estilo adusto de $D$. Justo Balanza, para venir a parar en la gracia chocarrera y grosera, saltándose todo respeto humano y divino, en aras de la predicada libertad de expresión de la que El Madrileño hace gala hasta el final de sus Cartas, retirándose de la palestra precisamente por considerar que aún no ha llegado el momento de disfrutar el supremo bien de la libertad total de expresión a que aspira el exaltado liberal que se oculta bajo la hiriente sonrisa de Sebastián de Miñano y Bedoya, hombre más para incluir en el periodismo político y en el folletín romántico que en las mansas filas del costumbrismo ligeramente satírico a que, equivocadamente, se le viene desviando por la simple lectura de los Lamentos. 
Se da también en Miñano, como en Larra, en muy pequeñas pero drásticas dosis, el ejercicio de la crítica, en el que no deja títere con cabeza.

Su ataque frontal a la obra y a las personas nos lo muestra como satírico y crítico impenitente en la reseña de la obra del $\mathrm{P}$. General de los capuchinos:

Ya habrá llegado a noticia de usted, o acaso habrá leído, una representación que tiene por título Observación respetuosa que hace al Rey y a las Cortes el padre general de los Capuchinos. Es de advertir que a esta suprema divinidad seráfica están unidos los honores y tratamiento de grande de España, a imitación sin duda de los apóstoles, que todos tuvieron excelencia. Yo hubiera deseado que se fijasen con alguna claridad los límites donde acaba la obligación del voto de obediencia en un fraile franciscano, porque, a mi entender, este punto daría mucha luz para otras diferentes cuestiones que yo sé que deben agitarse.

$$
\text { (C. M.-2 }{ }^{\mathrm{a}}, \text { V. también C. M. }-3^{\mathrm{a}} \text {.) }
$$

Con parecido mordiente arremete contra el folleto Los ilustres haraganes o apología razonada de los mayorazgos:

[...] Y aunque yo debiera estar ya bastante escarmentado de comprar papeluchos de circunstancias, sin embargo esto de estar en verso y parecerme por el título cosa de sátira y burleta me hizo caer en la tentación de enviar a buscarlo. Le abrí en efecto y lo primero que vieron mis ojos fue una octava que le sirve de epígrafe, tomada en aquel detestable poema de antaño Ilamado $E l$ peso duro. Bien conocí, desde luego, que quien se atreve a tomar por texto un trozo de la obra más estúpida que han conocido los siglos no podría menos de tener los sesos hechos suero. Efectivamente, no piense usted que hay en la tal sátira ni siquiera una linea de desperdicio, porque tan desatinado es el primer terceto como el último, y tan bobitonto aparece el autor en el epígrafe como en el cuerpo de la sátira. Ignoro quién pueda ser este desgraciado; pero sea quien fuere, desde ahora le declaro y reconozco por el primer tonto de Europa, aunque tenga más títulos y más diplomas que cuantos académicos hubo en la Argamasilla. Si me queda algún rato ocioso, me entretendré un poquito en burlarme de él; pero por de pronto incluyo a usted el fatal folleto, que le convencerá de que todavía hay escritores capaces de de competir en lo necio con el mismo autor del Peso duro y de la Egilona.

(C. $\left.M \cdot-3^{\mathrm{a}}.\right)$

Lanza todo su veneno anticlerical contra el Arzobispo de Valladolid, por su representación, enviada a las Cortes, relativa a que desde luego queden sin efecto todos los decretos y providencias tomadas hasta ahora en asuntos eclesiásticos:

Parece ser que lo que a S. E. le ha llegado al oído es el terrible contraste que se observa entre nuestros antiguos reyes, que fundaban y enriquecían los monasterios, y nuestras actuales Cortes, que con un solo golpe de pluma los han mandado desocupar para destinarlos a otros usos profanos. Bendita sea mil veces la boca de este devoto prelado, que pudiendo haber disparado una 
excomunión a mata candelas con la cual se hubieran quedado patitiesos toditos los diputados, se ha contentado con igualarlos a Lutero y a los miembros de la cismática asamblea de Francia...

(C. $\left.M \cdot-6^{\mathrm{a}}.\right)$

La violencia dialéctica, combinada con la sátira, es el arma fuerte del terrible ataque lanzado contra la Miscelánea. (C. M. $-8^{\mathrm{a}}$.)

Altamente despiadada resulta la crítica al n. 304 de la Miscelánea y el n. ${ }^{\circ} 44$ de El Universal:

Pero me detiene para enviárselo la vergonzosa repugnancia que siento de que ni por un instante estén mezcladas mis ideas con los asquerosos abortos de su pluma. ¡Harta compasión me causan sus infelices redactores, cuando los veo sujetos a su cómitre que los obliga a combatir contra sus propios intereses!

$$
\text { (C. } \left.M \cdot-14^{\mathrm{a}} .\right)
$$

Se nos revela así por el propio vocabulario y por la virulencia de su dialéctica un Miñano muy distinto del que estamos acostumbrados a ver desde la benévola imagen del charlatán político y Pobrecito Holga$z a ́ n$, que él mismo ha prefabricado:

Mi querido amigo: tiene usted tan poco cuidado y reserva con las cartas que yo le escribo, que al fin y al cabo llegan a hacerse públicas, a fuerza de correr de mano en mano, vienen a parar en las de algunos lectores descontentadizos y malhumorados, que apenas leen algunos periodos cuando empiezan a maldecir de ellas y de su autor. ¡Qué cosa tan insulsa y tan sin sustancia dicen algunos, y cuánto más valiera que este mentecato se ocupara en mejorarse a sí mismo, que no en corregir a los demás! ¡Oh, qué exceso de bilis, dicen otros, cuán poco gracejo le ha dado Dios para hacerla soportable! ¿Quién es este insolente, replican algunos, que sin haber recibido misión tácita ni expresa, se atreve a predicar contra toda especie de vicios, sin tener miramiento al lugar donde residen, ni a las personas que los practican? ¿Pues qué, no hay más de medir a todos por un rasero y exponer a la risa pública hasta los hombres que están más satisfechos de su fama y de la aceptación popular? ¿Si se pensará convertirnos este nuevo payaso de la constitución con sus ironías forzadas, habiendo sabido nosotros resistir a otros razonamientos que parecían verdaderas demostraciones?

$$
\text { (C. } \left.M,-9^{\text {a }} .\right)
$$

Dejando a un lado al erudito, no nos queda más remedio que rendirnos ante la maestría de esta trilogía de Cartas, justamente famosas, por cuanto en el leve período de un año su autor ha pasado del mero cuadro dieciochesco de costumbres - del que muchos críticos no han sabido aún separarle- al frío estilo de las Cartas de D. Justo Balanza, no exentas todavía de ingeniosidades y de vueltas al cuadro costumbrista, aunque con tono más oscurantista y quevedesco ya. El predominio de las ideas y la sistemática crítica detractora de las instituciones tradicionales son típicos de lo que el autor califica de estilo serio. 
Finalmente, el creciente sentido del periodismo político (no ajeno a los insultos, al «adoctrinamiento» y a la dureza del lenguaje) engendra una sangrante «pepitoria de caricaturas velleinclanescas» en torno al mundo político.

Paralelo desarrollo se observa en la variedad y adecuación del lenguaje, cuyo colorido culmina en la crítica de periódicos y folletos de autores enemigos.

El tono liberal y de exaltación ideológica de la libertad llevan el ingenuo cuadro de costumbres de El Pobrecito Holgazán al corrosivo y sombrío paisaje político descrito por El Madrileño.

Rápido aprendizaje, propio del instinto literario de Sebastián Miñano, desconcertante y polifacético talento de nuestro periodismo.

Ni su estilo se acerca a Cervantes, como pretendió hacernos creer el filial cariño de Ochoa, ni resulta el «costumbrista de segunda clase» que quiso hacernos ver el P. Blanco García, ni tampoco es el «charlatán descocado" en que quisieron convertirle sus enemigos de El Especta$d o r$. Más bien tenemos en Miñano un preclaro valor del periodismo político y un exaltado defensor de toda libertad; no sólo un apasionado y revolucionario romántico que supo adelantarse en muchas millas al periodismo de su época, sino además un claro precursor del mejor periodismo satírico-político de todos los tiempos. 